\title{
Lung function in primary ciliary dyskinesia: breaking the myth that this is a mild disease
}

\author{
Sejal Saglani \\ Affiliation: National Heart and Lung Institute, Imperial College London, London, UK.
}

Correspondence: Sejal Saglani, National Heart and Lung Institute, Imperial College London, 368 Sir Alexander Fleming Building, Exhibition Road, London, SW7 2AZ, UK. E-mail: s.saglaniđimperial.ac.uk

@ERSpublications

Early diagnosis and intervention is essential to prevent progressive lung damage in primary ciliary dyskinesia http://ow.ly/JMCE3018YVa

Cite this article as: Saglani S. Lung function in primary ciliary dyskinesia: breaking the myth that this is a mild disease. Eur Respir J 2018; 52: 1801365 [https://doi.org/10.1183/13993003.01365-2018].

Primary ciliary dyskinesia (PCD) is a chronic suppurative lung disease that is recessively inherited and has marked clinical phenotypic heterogeneity [1]. The autosomal recessive inheritance and impaired mucociliary clearance secondary to ciliary dysfunction mean the condition is often compared to cystic fibrosis both in terms of outcomes [2] and management [3]. Indeed, even though both are chronic suppurative lung diseases associated with bronchiectasis, to date PCD has often been considered mild and relatively benign compared to cystic fibrosis.

This assumption is brought into question by the data presented in the article by HaLBeISEN et al. [4] in the current issue of the European Respiratory Journal. The international PCD (iPCD) Cohort is a retrospectively collected data set that contains diagnostic test results, clinical phenotype, growth and lung function [5]. The iPCD Cohort contains data on over 3000 patients with a clinical phenotype of PCD from 18 countries. Reliable data for spirometry were analysed from 991 patients aged $\geqslant 6$ years in the current study by HALBEISEN et al. [4], and compared to reference values for age-matched healthy individuals and to published data from patients with cystic fibrosis. All PCD patients, regardless of age or country of origin, had lower lung function than healthy controls. Children had the best lung function, which deteriorated with increasing age. Interestingly, at age 6-9 years, spirometry was reduced to a similar extent to that seen in children with cystic fibrosis. However, the impact of early diagnosis and management on lung function outcomes remains uncertain, since there was no significant relationship between age at diagnosis and current lung function. Despite this, the findings of a reduction in lung function in early childhood similar to that in cystic fibrosis, and lower lung function in adults than children, highlight the importance and need for aggressive early management. Interestingly, and akin to the early functional abnormalities reported by HALBEISEN et al. [4], airway pathological changes assessed in endobronchial biopsies from age-matched children with PCD and cystic fibrosis have also shown similar inflammation and remodelling [6], suggesting structural damage also occurs early and to the same extent as in cystic fibrosis. Although the data highlight pathophysiological similarities between PCD and cystic fibrosis and the need for early and aggressive therapy for PCD, the need for unified, multicentre randomised controlled trials that will provide specific evidence for efficacy of therapeutic interventions in PCD remains. A recent trial of hypertonic saline in PCD has been undertaken and should be commended [7], but it was a single-centre study and underpowered, thus limiting any definitive conclusions about the impact of this intervention on the chosen primary outcome. It is encouraging to see that a multicentre 
European interventional trial, including both children and adults, is being undertaken to assess the efficacy of maintenance azithromycin therapy in confirmed PCD [8]. This will help to provide information about the role of the anti-inflammatory and anti-infective actions of azithromycin in improving outcomes in PCD. It would be wrong to extrapolate findings from trials in cystic fibrosis and assume benefit in PCD.

A significant relationship between specific microtubular ultrastructural defects and low lung function measured by spirometry was found in the current study by HALBEISEN et al. [4], which is in line with a recent report that has shown a relationship between worse lung clearance index and microtubular ultrastructural defects [9]. The fact that two reports (which have used different lung function measures) show a relationship between specific ultrastructural defects and lung function raises interesting mechanistic questions about disease severity and a spectrum of effective mucociliary clearance mediated by the specific ultrastructural defect. The marked disease heterogeneity within PCD is recognised [1] and may partly be explained by efficiency of ciliary function determined by specific ultrastructural defects. For now, the data relating worse lung function to microtubular defects should at least alert clinicians to the potential need for more aggressive management in these patients to try to minimise progressive decline.

The results presented in the current study by HaLBEISEN et al. [4] undoubtedly demonstrate the advantages of multicentre collaboration and data collection for rare lung diseases. The time and resources required for such efforts are not small, but have already shown significant benefit $[5,10,11]$. However, the limitations of the study, which are acknowledged by the authors, and include a lack of information relating lung function to airway structure from imaging, absence of relationships between spirometry and airway pathogens and the absence of longitudinal data showing change in the same patients over time, underscore the need for such data collection to be undertaken prospectively [12]. The advantages of imaging techniques include the ability to visualise regional disease compared to the global abnormalities detected by spirometry. Although computed tomography (CT) imaging has been used clinically in cystic fibrosis, studies reporting changes in PCD with specific relationships between structural and functional abnormalities are lacking. However, there is some evidence of similar magnetic resonance imaging (MRI) and lung function changes in PCD and cystic fibrosis subjects with mild pulmonary disease [13]. Inclusion of CT imaging and MRI is being encouraged in randomised controlled interventional trials in cystic fibrosis to allow improved assessments of cystic fibrosis disease progression [14]. Given that spirometry was less impaired in young adults with PCD in the study by HALBEISEN et al. [4], inclusion of imaging modalities to allow investigation of longitudinal change in structure-function relationships, especially to assess disease progression and regional or focal changes, needs to be encouraged for PCD. The current study was a retrospective analysis of data that had been collected at different centres and, although the parameters included were all objective and robust, it is a shame to miss the opportunity for maximal data acquisition when not undertaken prospectively. Prospective and longitudinal data collection, which includes unified assessments and time-points at all centres, will be invaluable to understand the long-term prognosis and to provide direction towards genotype- and phenotype-guided interventions. The relationship between ciliary ultrastructural defect and lung function found by HALBEISEN et al. [4] presents an example of how future mechanistic studies might be designed to investigate epithelial and mucociliary function in specific ultrastructural phenotypes to identify novel therapeutic interventions.

Conflict of interest: None declared.

\section{References}

1 Rubbo B, Lucas JS. Clinical care for primary ciliary dyskinesia: current challenges and future directions. Eur Respir Rev 2017; 26: 170023.

2 Wijers CD, Chmiel JF, Gaston BM. Bacterial infections in patients with primary ciliary dyskinesia: comparison with cystic fibrosis. Chron Respir Dis 2017; 14: 392-406.

3 Schofield LM, Duff A, Brennan C. Airway clearance techniques for primary ciliary dyskinesia; is the cystic fibrosis literature portable? Paediatr Respir Rev 2018; 25: 73-77.

4 Halbeisen FS, Goutaki M, Spycher BD, et al. Lung function in patients with primary ciliary dyskinesia: an iPCD Cohort study. Eur Respir J 2018; 52: 1801040.

5 Goutaki M, Halbeisen FS, Spycher BD, et al. Growth and nutritional status, and their association with lung function: a study from the international Primary Ciliary Dyskinesia Cohort. Eur Respir J 2017; 50: 1701659.

6 Hilliard TN, Regamey N, Shute JK, et al. Airway remodelling in children with cystic fibrosis. Thorax 2007; 62: $1074-1080$.

7 Paff T, Daniels JM, Weersink EJ, et al. A randomised controlled trial on the effect of inhaled hypertonic saline on quality of life in primary ciliary dyskinesia. Eur Respir J 2017; 49: 1601770.

8 Kobbernagel HE, Buchvald FF, Haarman EG, et al. Study protocol, rationale and recruitment in a European multi-centre randomized controlled trial to determine the efficacy and safety of azithromycin maintenance therapy for 6 months in primary ciliary dyskinesia. BMC Pulm Med 2016; 16: 104.

9 Irving S, Dixon M, Fassad MR, et al. Primary ciliary dyskinesia due to microtubular defects is associated with worse lung clearance index. Lung 2018; 196: 231-238. 
10 Goutaki M, Maurer E, Halbeisen FS, et al. The international primary ciliary dyskinesia cohort (iPCD Cohort): methods and first results. Eur Respir J 2017; 49: 1601181.

11 Haver K. The time is right for an international primary ciliary dyskinesia disease registry. Eur Respir J 2017; 49: 1602143.

12 Amirav I, Roduta Roberts M, Mussaffi H, et al. Collecting clinical data in primary ciliary dyskinesia - challenges and opportunities. F1000Res 2016; 5: 2031.

13 Maglione M, Montella S, Mollica C, et al. Lung structure and function similarities between primary ciliary dyskinesia and mild cystic fibrosis: a pilot study. Ital J Pediatr 2017; 43: 34.

14 Szczesniak R, Turkovic L, Andrinopoulou ER, et al. Chest imaging in cystic fibrosis studies: what counts, and can be counted? J Cyst Fibros 2017; 16: 175-185. 